\title{
Fatores de risco do câncer gástrico: Revisão de literatura
}

\section{Gastric cancer risk factors: Literature review}

Factores de riesgo del cáncer gástrico: Revisión de la literatura

Rafael Pavão Gonçalves

ORCID: https://orcid.org/0000-0002-5234-3086 Universidade Ceuma, Brasil

E-mail: Metodologiacientifica42@gmail.com

Ricardo Soares Coelho

ORCID: https://orcid.org/0000-0002-5747-6486 Centro Universitário Metropolitano da Amazônia, Brasil

E-mail: ricardosoarescoelh@gmail.com

Lucas Felipe Albuquerque da Silva

ORCID: https://orcid.org/0000-0003-3557-2167 Universidade Ceuma, Brasi

E-mail: lucasfalbuquerque @hotmail.com

Matheus Albert de Souza Puerro

ORCID: https://orcid.org/0000-0002-8464-0245 Centro Universitário Metropolitano da Amazônia, Brasil

E-mail: aalbertpuerro@gmail.com

Paulo Gabriel da Rocha Moura

ORCID: https://orcid.org/0000-0002-1606-6595

Universidade Estadual do Maranhão, Brasil E-mail: paulogmoura1@gmail.com

Suzana Bastos Jácome de Souza ORCID: https://orcid.org/0000-0001-6530-4871 Instituto de Educação Superior do Vale do Parnaíba, Brasil

E-mail: suzanabastosjacom@bol.com.br

Luciano Silva Mendonça

ORCID: https://orcid.org/0000-0002-2182-0919

Universidade Estadual do Maranhão, Brasil

E-mail: lucianomendonca@gmail.com

Bianca Santos Macedo Martins Granja

ORCID: https://orcid.org/0000-0002-1907-7089

Universidade Estadual do Maranhão, Brasil E-mail: biancasantosm3@hotmail.com

Luiza Helena Everton Coelho

ORCID: https://orcid.org/0000-0002-8377-4540 Universidade Ceuma, Brasil

E-mail: Metodologiacientifica42@gmail.com

Pricilla Estephane Da Costa Carvalho ORCID: https://orcid.org/0000-0003-2251-6473 Universidade Ceuma, Brasil

E-mail: Metodologiacientifica42@gmail.com

Flaviana Manuella Froes Abreu Pavão ORCID: https://orcid.org/0000-0001-7055-6934 Universidade Ceuma, Brasil

E-mail: flavianaapavaoo@ hotmail.com

Gabriel De Sousa Macedo

ORCID: https://orcid.org/0000-0003-3445-0379 Universidade Ceuma, Brasil

E-mail: gdesousa011110@gmail.com

Samantha Cunha Vieira

ORCID: https://orcid.org/0000-0002-8831-2855 Universidade Ceuma, Brasil

E-mail: samanthacvieiraaa@gmail.com

José Roberto Lopes Costa Filho

ORCID: https://orcid.org/0000-0002-4329-1536

Universidade Ceuma, Brasil

E-mail: med.robertoofilhooo@hotmail.com

Mikael Coutinho Silva

ORCID: https://orcid.org/0000-0003-2243-9690

Universidade Ceuma, Brasil

E-mail: mikael48888@hotmail.com 
Resumo

Propôs-se realizar com este estudo, uma revisão da literatura a respeito dos fatores de risco para o desenvolvimento do câncer gástrico. Os dados foram coletados mediante revisão da literatura utilizando os descritores em ciência e saúde deCS/ MeSH: Câncer gástrico, Helicobacter pylori, Fator de risco, tomando como base artigos publicados por meio das bases de dados científicas: Scielo, Lilacs, MedLine e Google Acadêmico, além de outras fontes como INCA Instituto Nacional de Câncer. Foram coletados um total de 27 artigos científicos, dos quais 8 se encontraram dentro 
dos critérios de exclusão, sobrando 14 trabalhos dentro dos critérios de inclusão. O câncer gástrico acomete muitas pessoas mundialmente, pois com o advento da globalização, mudou-se o estilo de vida, desenvolvendo-se hábitos prejudiciais à saúde e que potencializam as chances de se desenvolver o câncer gástrico, além dos fatores intrínsecos, como os genético-familiares. O consumo excessivo de carne é um dos fatores que pode levar a uma neoplasia maligna, visto que substâncias liberadas na sua preparação podem ser cancerígenas. Bem como, a helicobacter pylori também possui ligação com a patogenia do câncer gástrico devido a capacidade de interação com as células do hospedeiro e a resposta inflamatória. Além disso, alterações genéticas podem contribuir para um possível tumor maligno, a inativação do gene P 53 que é um gene supressor de tumor, por exemplo. De forma geral, fatores ambientais, bem como hábitos alimentares, tabagismo e fatores genéticos, são possíveis fatores que podem levar ao câncer gástrico.

Palavras-chave: Câncer gástrico; Helicobacter pylori; Fator de risco.

\begin{abstract}
It was proposed to carry out with this study, a review of the literature regarding risk factors for gastric cancer. Data were collected through a literature review using the descriptors in science and health of CS/ MeSH: Gastric cancer, Helicobacter pylori, Risk factor, based on articles published through the scientific databases: Scielo, Lilacs, MedLine and Google Scholar, in addition to other sources such as INCA - Instituto Nacional de Câncer. A total of 27 scientific articles were collected, of which 8 met the exclusion criteria, leaving 14 works within the inclusion criteria. Gastric cancer affects many people worldwide, because with the advent of globalization, the lifestyle has changed, developing habits that are harmful to health and that enhance the chances of developing gastric cancer, in addition to intrinsic factors such as genetics. -relatives. Excessive consumption of meat is one of the factors that can lead to a malignant neoplasm, since substances released in its preparation can be carcinogenic. As well, helicobacter pylori is also linked to the pathogenesis of gastric cancer due to its ability to interact with host cells and the inflammatory response. In addition, genetic alterations can contribute to a possible malignant tumor, the inactivation of the P 53 gene, which is a tumor suppressor gene, for example. In general, environmental factors, as well as eating habits, smoking and genetic factors, are possible factors that can lead to gastric cancer.
\end{abstract}

Keywords: Stomach cancer; Helicobacter pylori; Cliff factor.

\title{
Resumen
}

Se propuso realizar con este estudio, una revisión de la literatura respecto a los factores de riesgo para el cáncer gástrico. Los datos fueron recolectados a través de una revisión bibliográfica utilizando los descriptores en ciencia y salud de CS/MeSH: Cáncer gástrico, Helicobacter pylori, Factor de riesgo, con base en artículos publicados a través de las bases de datos científicas: Scielo, Lilacs, MedLine y Google Scholar, además de otros fuentes como INCA Instituto Nacional de Câncer. Se recogieron un total de 27 artículos científicos, de los cuales 8 cumplieron con los criterios de exclusión, quedando 14 trabajos dentro de los criterios de inclusión. El cáncer gástrico afecta a muchas personas a nivel mundial, pues con el advenimiento de la globalización, el estilo de vida ha cambiado, desarrollando hábitos nocivos para la salud y que aumentan las posibilidades de desarrollar cáncer gástrico, además de factores intrínsecos como la genética. -parientes. El consumo excesivo de carne es uno de los factores que pueden derivar en una neoplasia maligna, ya que las sustancias liberadas en su preparación pueden ser cancerígenas. Además, Helicobacter pylori también está relacionado con la patogenia del cáncer gástrico debido a su capacidad para interactuar con las células huésped y la respuesta inflamatoria. Además, las alteraciones genéticas pueden contribuir a un posible tumor maligno, la inactivación del gen P 53, que es un gen supresor de tumores, por ejemplo. En general, los factores ambientales, así como los hábitos alimenticios, el tabaquismo y los factores genéticos, son posibles factores que pueden conducir al cáncer gástrico.

Palabras clave: Cáncer de estómago; Helicobacter pylori; Factor de acantilado.

\section{Introdução}

O número de novos casos de câncer no mundo tem aumentado de maneira considerável a cada ano, tornando-se um grave problema de saúde pública. Entre as principais causas que aumentam a incidência de neoplasias do trato digestório e do câncer de esôfago estão os fatores dietéticos, como o consumo exagerado de gorduras e a baixa ingesta de fibras, entre outros, como o fumo, o álcool e o sedentarismo (Baúet al., 2011).

A chamada classificação de Bormann, descreve as lesões cancerígenas de acordo com seus aspectos macroscópicos em tipos I (lesão elevada e polipóide), II (lesão ulcerada com margens bem definidas), III (lesão ulcerada parcialmente infiltrativa com bordas irregulares) e IV (Lesão difusamente infiltrativa) (Todescatto, 2017).

O câncer gástrico (CG) é uma das neoplasias malignas mais comuns e apresenta alta mortalidade, sendo considerado a segunda causa de morte de câncer. O desenvolvimento do câncer gástrico é multifatorial, envolvendo tanto aspectos 
ambientais como genéticos. Sabe-se que a doença surge com as alterações da mucosa gástrica, que sob ação de vários fatores, adquire um fenótipo progressivamente regressivo, através da substituição das células normais do estômago por células indiferenciadas (Baú et al.,2011).

As causas do câncer são variadas, podendo ser externas ou internas ao organismo, estando inter-relacionadas. As causas externas referem-se ao meio ambiente e aos hábitos ou costumes próprios de uma sociedade. As causas internas são, na maioria das vezes, geneticamente predeterminadas e estão ligadas à capacidade de o organismo se defender das agressões externas. Os tumores podem ter início em diferentes tipos de células. Quando começam em tecidos epiteliais, como pele ou mucosas, são denominados carcinomas (Cruz et al., 2018).

Esse processo de transmutação da mucosa gástrica, em parte conhecido, ocorre a longo prazo e sugere que os fatores de risco para CG atuam por um longo período (Baú et al., 2011). Dentre os fatores de risco ambientais, é importante citar o tabagismo e a infecção pelo Helicobacter pylori, por exemplo. Já dentre os fatores genéticos, cita-se o grupo sanguíneo A, a inativação de genes supressores p53 e a redução da E-caderina. O objetivo do seguinte trabalho é realizar uma revisão de literatura a respeito dos fatores de risco para o câncer gástrico.

\section{Metodologia}

Os procedimentos metodológicos de um trabalho acadêmico é um processo lógico com finalidade principal de atingir um determinado fim ou para se chegar ao conhecimento de um determinado assunto (Conforto et al., 2011).

Dessa forma, utilizando- se os critérios de inclusão e exclusão supracitados, a metodologia desta pesquisa pode ser realizada de forma a alcançar resultados efetivos e reduzir possíveis erros, tornando esta revisão mais rigorosa cientificamente (Conforto et al., 2011).

Realizou-se uma revisão de literatura com busca em bases de dados eletrônicos como PubMed, Google scholar e Scielo, considerando artigos publicados em português, inglês e espanhol entre os anos de 2013 e 2021. Foram cruzados com o operador booleano and os descritores "Câncer gástrico" e "revisão de literatura". Os critérios de inclusão foram: artigos publicados em português e em inglês, entre os anos de 2010 a 2021 e disponíveis na íntegra. Como critério de exclusão considerou-se a não pertinência ao tema.

Foram coletados um total de 27 artigos científicos e sites, dos quais 8 se encontraram dentro dos critérios de exclusão, sobrando 14 trabalhos dentro dos critérios de inclusão.

\section{Resultados e Discussão}

O consumo excessivo de carne, tanto frita, grelhada ou assada, é um fator de risco para o câncer gástrico. Assim, o elevado consumo de carne bovina ou carne processada incide com o adenocarcinoma gástrico e de esôfago (Machlowska, 2020).

Alguns modos de preparo da carne também se associam com o aparecimento do câncer de estômago, como o churrasco, que por expor o alimento diretamente ao fogo, produz componentes carcinogênicos na sua superfície, como os hidrocarbonetos aromáticos policíclicos e aminas heterocíclicas e eleva as chances de adenocacinoma gástrico (Machlowska, 2020).

Por meio da saliva, o nitrato presente em alimentos, como carnes curados e embutidos (picles, salsichas e salames), é transformado em nitrito. $\mathrm{O}$ consumo de compostos nitrosos habitualmente provoca o aumento de radicais livres, resultando em lesão celular e redução na produção de muco, o qual é um fator de proteção da mucosa gástrica, aumentando o risco de câncer gástrico (Park, 2018). 
A fumaça do tabaco é oncogênica para os seres humanos. Nela há substâncias carcinogênicas de diferentes classificações químicas que provocam, iniciam e promovem o câncer. Elas alteram o DNA das células, o que levam ao câncer no estômago e em outros órgãos do corpo. As substâncias químicas do fumo provocam um processo inflamatório crônico, fazendo com o sistema imunológico de defesa tente reverter os danos nas células e no material genético causado pelo tabagismo. Esse comprometimento do sistema de defesa provoca muitas doenças, como o câncer (Magalhães LP, 2008).

O risco de câncer aumenta de acordo com o início precoce de uso de tabaco, do tempo e da quantidade que a pessoa se expõe. Além de causar câncer, o tabagismo também atrapalha o tratamento e o controle de neoplasias em geral (Mirra at al., 2013).

A associação da bactéria Helicobacter pylori com o câncer gástrico (CG) é devido a infecção da mucosa do estômago provocando afecções localizadas de gravidade variável, tais como gastrite, úlceras pépticas e o próprio CG. Esta bactéria caracteriza-se por ter capacidade de interação com células do hospedeiro de forma a garantir sua permanência por longo tempo. Mesmo a H. pylori sendo responsável por uma grande diversidade de doenças, a maioria dos indivíduos infectados por ela não apresentam sintomatologia. Além disso, a capacidade de sobrevivência da H. pylori em ambiente tão ácido como o fornecido pelo estômago é considerado uma característica singular desta bactéria, deve-se a excreção de amônia que a protege neutralizando parcialmente esta acidez (Barbosa et al., 2010) (Fitzgerald, 2010).

Após a infecção, a H. pylori ativa múltiplas vias intracelulares em células epiteliais, tais como MAOK, NK-kB, ativador d e proteína (AP) -1, Wnt/â-catenina, PI3K, transdutores de sinal e ativadores de transcrição 3 (STAT3), ciclooxigenase2, que afetam as funções celulares tendo como consequência a produção acentuada de citocinas inflamatórias, proliferação e diferenciação de células epiteliais, alteração das taxas de apoptose, e o mais interessante, resultam na transformação oncogênica de células epiteliais. Os fatores de virulência a exemplo da citoxina CagA, a citoxina vacuolizadora e as proteínas de membrana externa (OMPs), são responsáveis por grande parte destes efeitos. A H. Pylori induz modificações epigenéticas, como a metilação do DNA e a alteração das histonas, que são importantes na transformação oncogênica (Park, 2018).

Experiências com animais têm sido realizadas para melhor compreensão do papel dos fatores de virulência da $\mathrm{H}$. pylori dando a possibilidade de observação dos mecanismos de indução da oncogênese. Em um experimento que foi utilizado um camundongo transgênico, demonstrou-se que a expressão de CagA em camundongos induziram vários tumores, hiperplasia epitelial gástrica, carcinomas gastrointestinais, pólipos hiperplásicos e doenças hematológicas malignas, como leucemia mielóide e Linfoma de célula B. Observação significante foi a ausência de sinais de gastrite ou inflamação sistêmica e identificação de câncer em células independentes. É importante lembrar que este estudo demonstrou que a proteína isolada é capaz de induzir o câncer, sem processo inflamatório, ressaltando assim o papel da Cag na tumorigênese como sendo oncoproteína (Park, 2018).

Além disso, estudos epidemiológicos demonstram o risco aumentado de até 6 vezes para o desenvolvimento de adenocarcinoma gástrico em humanos infectados pelo H. pylori. $\mathrm{O}$ adenocarcinoma gástrico possui altas taxas de incidência em países asiáticos como China e Japão, principalmente quando comparadas com as taxas encontradas no ocidente. Observaram incidência de 2,9\% de câncer gástrico em 1246 japoneses infectados pelo H.pylori, acompanhados prospectivamente e nenhum caso em 280 pacientes que apresentaram exames com $\mathrm{H}$. pylori negativos. Nesse contexto, outros estudos têm mostrado possíveis associações entre a infecção pelo H. pylori e as lesões gástricas precursoras de neoplasia (Amaya Arbeláez, M. I., 2020).

Estima-se que 50\% da população mundial esteja infectada pela H.pylori e que em torno de 79\% dos novos casos de câncer gástricos diagnosticados anualmente estejam relacionados a infecção por esse patógeno. Devido a isso, a Helicobacter 
pylori é considerada uma carcinogênica classe I pela Agência Internacional de Pesquisa sobre Câncer (Park, 2018), (Besagio, 2021).

Dessa forma, há unanimidade entre os autores dos artigos lidos sobre a relação da H. pylori ao câncer gástrico. Sendo que, grande parte da população possui essa bactéria presente no estômago e não apresenta nem uma espécie de sintoma, ao passo que, outros portadores desenvolvem o câncer gástrico. O CG seria o estágio mais avançado da infecção por essa bactéria. No entanto, outras doenças também podem manter relação com a Helicobacter pylori, como, a gastrite e a úlceras pépticas (Rodrigues, 2019).

Foi descrito pela primeira vez em 1998, através de estudos realizados em três famílias Maori da Nova Zelândia, onde a incidência da doença ocorria em indivíduos entre 14 e 40 anos de idade, quando dados pesquisados mostram que o risco maior está em idades iguais ou acima de 80 anos em membros de uma mesma família com CGDH, dividindo-se em 67\% de chance para o sexo masculino e $83 \%$ de chance para o sexo feminino. Para mulheres, o risco cumulativo de câncer de mama é de 39\% e a combinação de câncer gástrico e de mama tem um risco de $90 \%$ em idade de 80 anos. Esta abordagem, no entanto, pode ser útil para aconselhamento genético, todavia, podem não ser aplicáveis para indivíduos sem o mínimo de histórico familiar, em quem o risco deve ser menor (Fitzgerald, 2010).

Acredita-se que os antígenos $\mathrm{ABO}$ estão relacionados com o câncer gástrico. Haenszel et al. sugerem, em pesquisa realizada, que o tipo sanguíneo A está mais relacionado com o câncer gástrico do tipo difuso (CGDH) em pacientes jovens, ou seja, abaixo de 50 anos. Já Yaghoobi et al. realizaram, à época, o que pode ter sido o primeiro trabalho de pesquisa relacionando o sangue tipo $\mathrm{O}$ como fator genético para câncer gástrico (Fitzgerald RC, 2010).

$\mathrm{O}$ câncer se forma quando há mutação genética em determinado oncogene concomitantemente com a inativação das proteínas P53, que são consideradas protetoras do genoma humano. Elas têm a função de verificação da cadeia de nucleotídeos a fim de procurar falhas nas trincas das bases nitrogenadas com a intenção de, em caso de DNA sem falha, liberar a duplicação ou, em caso de defeito, a célula poderá corrigir o código genético através de proteínas de reparo ou realizar a apoptose. Pela sua natureza e por ser importante na prevenção do desenvolvimento de tumores, a proteína P53, que é codificada por um gene situado no cromossomo 17, que leva a denominação de gene supressor de tumor, é indicativa de pior prognóstico nos casos de câncer do cólon, pulmão e mama. Já no câncer gástrico, a proteína P53 como prognóstico é controverso e foi sendo avaliado com outras variáveis, tais como: idade, sexo, infiltração na parede gástrica "T", grau de diferenciação histológica, tipo histológico de Laurén, estadiamento e comprometimento linfonodal (Rocha et al., 2004).

Em relação às chances de desenvolver câncer de estômago, sabe-se que há múltiplos fatores de risco que podem impactar no seu surgimento. Nesse sentido, entre os principais está o histórico familiar, que pode aumentar em até três vezes as chances de um indivíduo desenvolver um carcinoma gástrico, com esse fator genético apresentando maior incidência em regiões da Ásia. Apesar disso, os fatores ambientais ainda têm um papel de extrema importância tanto na prevenção quanto no aumento da probabilidade de desenvolver a doença. Por conseguinte, entre os fatores ambientais mais relevantes se encontra a infecção por Helicobacter pylori. (Machlowska, 2020); (Besagio, 2021).

\section{Conclusão}

A partir dos dados obtidos e analisados neste trabalho, pôde-se identificar um certo padrão nos possíveis tipos de causas do câncer gástrico. Os resultados foram obtidos baseando-se em pesquisas realizadas em trabalhos publicados, que mostram o papel de cada fator de risco no desenvolvimento da doença. Observa-se, assim, que o ser humano está sujeito mesmo que não tenha conhecimento, à fatores de risco, que os expõem à doença, das mais variadas formas. 
De forma geral, fatores ambientais, bem como hábitos alimentares, tabagismo e fatores genéticos, são possíveis fatores que podem levar ao câncer gástrico. Os autores revisados, quase em unanimidade, concordam que fatores ambientais, bem como hábitos alimentares, tabagismo e obesidade, são possíveis fatores que podem levar ao câncer gástrico.

Se tratando dos fatores genéticos, não há discordância entre os autores revisados sobre a hereditariedade, tipos sanguíneos e inativação da proteína P53, todos afirmam que existe a influência dos fatores citados. Em suma, os artigos pesquisados mostram um panorama sobre os fatores de risco e como eles podem atuar no desenvolvimento do câncer gástrico. Além disso, nota-se a necessidade de novas pesquisas sobre a temática.

\section{Referências}

Baú, F. C., \& Huth, A. (2011). Fatores de risco que contribuem para o desenvolvimento do câncer gástrico e de esôfago. Revista contexto \& saúde, 11(21), 1624.

Cruz, A. I. B. M., Pinto, L. F. R., Thuler, L. C. S., \& Bergmann, A. (2018). Perfil dos Pacientes com Câncer de Esôfago Diagnosticados entre 2001 e 2010 no Brasil. Revista Brasileira de Cancerologia, 64(4), 471-477.

Conforto, E. C., Amaral, D. C., \& Silva, S. D. (2011). Roteiro para revisão bibliográfica sistemática: aplicação no desenvolvimento de produtos e gerenciamento de projetos. Trabalho apresentado, 8 .

Machlowska, J., Baj, J., Sitarz, M., Maciejewski, R., \& Sitarz, R. (2020). Gastric cancer: epidemiology, risk factors, classification, genomic characteristics and treatment strategies. International journal of molecular sciences, 21(11), 4012.

Park, J. Y., Forman, D., Waskito, L. A., Yamaoka, Y., \& Crabtree, J. E. (2018). Epidemiology of Helicobacter pylori and CagA-positive infections and global variations in gastric cancer. Toxins, 10(4), 163.

Mirra, A. P., Reichert, J., Silva, C. A. R., Martins, S. R., Meirelles, R. H. S., \& Issa, J. S. (2013). Evidências científicas sobre tabagismo para subsídio ao Poder Judiciário [Internet]. São Paulo: $A M B, 12$.

Magalhães, L. P., Oshima, C. T. F., Souza, L. G., Lima, J. M. D., Carvalho, L. D., \& Forones, N. M. (2008). Variação de peso, grau de escolaridade, saneamento básico, etilismo, tabagismo e hábito alimentar pregresso em pacientes com câncer de estômago. Arquivos de gastroenterologia, 45(2), 111-116.

Carvalheira, J. B., \& Saad, M. J. (2006). Doenças associadas à resistência à insulina/hiperinsulinemia, não incluídas na síndrome metabólica. Arquivos Brasileiros de Endocrinologia \& Metabologia, 50, 360-367.

Amaya Arbeláez, M. I. (2020). Análise da expressão de proto-oncogenes e genes supressores tumorais em células epiteliais orais normais e neoplásicas promovida por metabólitos de biofilmes simples e misto de Candida albicans e Staphylococcus aureus.

Rocha, F. T. R., Lourenço, L. G., Jucá, M. J., Leal, A. T., \& Paz, A. M. D. C. D. (2004). Expressão da proteína p53 no adenocarcinoma gástrico: correlação clínica, anatomopatológica e significância prognóstica. Revista do Colégio Brasileiro de Cirurgiões, 31, 186-193.

Besagio, B. P., de Andrade, E. C., Cardoso, G. G., Couto, L. C., Santini, J. X., Nunes, P. L. P., \& de Carvalho, F. B. (2021). Câncer gástrico: Revisão de literatura Gastric Cancer: A Literature Review. Brazilian Journal of Health Review, 4(4), 16439-16450.

Fitzgerald, R. C., Hardwick, R., Huntsman, D., Carneiro, F., Guilford, P., Blair, V., ... \& Caldas, C. (2010). Hereditary diffuse gastric cancer: updated consensus guidelines for clinical management and directions for future research. Journal of medical genetics, 47(7), 436-444.

Conforto, E. C., Amaral, D. C., \& Silva, S. D. (2011). Roteiro para revisão bibliográfica sistemática: aplicação no desenvolvimento de produtos e gerenciamento de projetos. Trabalho apresentado, 8 .

Baú, F. C., \& Huth, A. (2011). Fatores de risco que contribuem para o desenvolvimento do câncer gástrico e de esôfago. Revista contexto \& saúde, 11(21), 1624.

Todescatto, Alexandra Damasio et al. Câncer gástrico. Acta méd.(Porto Alegre), p. [6]-[6], 2017. 